\title{
Rapid HPLC Method for Determination of Parachloroaniline in Chlorhexidine Antiseptic Agent in Mouthrinses, Ophthalmic and Skin Solution
}

\author{
Alain Nicolay, Estelle Wolff, Marie-France Vergnes, Jacques Kaloustian, Henri Portugal \\ Faculty of Pharmacist, Institut National de la Recherche Agronomique, Marseille, France \\ E-mail:alain.nicolay@univmed.fr \\ Received January 18, 2011; revised February 19, 2011; accepted May 30, 2011
}

\begin{abstract}
We described a simple and rapid method to quantify simultaneously chlorhexidine (CHD) and its major metabolite, para Chloroaniline (pCA) by HPLC with UV detection without the additional need of mobile-phase amine modifiers or ion-pairing reagents, with good resolution between pCA and CHD, symmetry peak of the compound and short run time. HPLC-UV analyses were performed using a Dionex ${ }^{\circledR}$ Summit liquid chromatograph (Dionex Corp, Sunnyvale, CA, USA). Chromatographic separations were carried out on a Luna ${ }^{\circledR} 150$ $\mathrm{mm} \times 3 \mathrm{~mm}$ i.d. column packed with $3 \mu \mathrm{m} \mathrm{CN}$ (cyano) particles (Phenomenex ${ }^{\circledR}$ ), guarded by an on-line filter. Mobile phase consist of methanol:water with sodium chloride with $0.02 \%$ of formic acid (55:45). Wavelengths for pCA and for CHD are 238 and $255 \mathrm{~nm}$ respectively. Influence of methanol and of sodium chloride content in the eluant has been studied. Linearity of CHD is very good, from 0.5 up to $21.2 \mu \mathrm{g} / 1$ while linearity of pCA is in the range of 0.05 to $10 \mu \mathrm{g} / 1$ with correlation coefficients above 0.999 . Resolution between the components is above 4, asymmetry is about 1.3 and 1.7 for pCA and CHD respectively and the run time is less than 5 minutes. This method has been applied to CHD solution of different medical devices. No interference has been reported, and the analysis of direct injection of solution, without any treatment is achieved in less than five minutes.In conclusion, we present a validated method for dosage of CHD and its major impurity pCA, known to be carcinogen, available into medical products or medicinal device for in-vitro diagnostic.
\end{abstract}

Keywords: Chlorhexidine, Chloroaniline, HPLC

\section{Introduction}

Chlorhexidine [CHD; 1,1'-hexamethylenebis[5-(4-chlorophenyl) biguanide]] has a wide spectrum of bactericidal and antiviral activity and is a common ingredient in various formulations ranging from skin disinfectants in healthcare products to antiplaque agents in dentistry $[1,2]$. The presence of two symmetrically positioned basic chlorophenyl guanide groups attached to a lipophilic hexamethylene chain (Figure 1) aid in rapid absorption through the outer bacterial cell wall, causing irreversible bacterial membrane injury, cytoplasmic leakage, and enzyme inhibition [3].

This molecule exists as various forms of salts: diacetate, dihydrochloride, or digluconate, mainly differing by their solubilizing abilities in aqueous or oily media. CHD digluconate (or gluconate), as most soluble in water or al- cohol, is the most used form in topical dermatology or cosmetic preparations. Aqueous solutions of CHD are most stable within the $\mathrm{pH}$ range of 5-8. Above $\mathrm{pH} 8.0$ CHD base is precipitated and in more acid conditions there is gradual deterioration of activity because the compound is less stable. Hydrolysis yields p-chloroan-<smiles>N=C(NCCCCCNC(=N)NC(=N)Nc1ccc(Cl)cc1)NC(=N)NC(=N)Nc1ccc(Cl)cc1</smiles>

Figure 1. Chemical structure of CHD and pCA. 
iline (pCA); the amount is insignificant at room temperature, but is increased by heating above $100^{\circ} \mathrm{C}$, especially at alkaline $\mathrm{pH}$ [4]. CHD diacetate is soluble in alcohol, glycerol, propylene glycol, polyethylene glycols. According to the manufacturer, 1 part CHD is soluble in 15 parts of $96 \%$ ethanol.

This cationic molecule (positively charged species) is thus generally compatible with other cationic materials, although compatibility will depend on the nature and relative concentration of the second cationic species. It is, however, possible for a reaction to occur between CHD and the counter-ion (anion) of a cationic molecule which is negatively charged, resulting in the formation of a less soluble CHD salt, which then may precipitate. CHD is incompatible with inorganic anions in all but extremely dilute solutions. CHD is also incompatible with organic anions, such as soaps, sodium lauryl sulphate, sodium carboxymethyl cellulose, alginates, and many pharmaceutical dyes. In certain instances, there will be no visible signs of incompatibility, but the antimicrobial activity may be significantly reduced because of the CHD being incorporated into micelles (ionic clusters) [5].

pCA is very toxic if inhaled, swallowed or absorbed through the skin. It may act as a human carcinogen. It is readily absorbed through the skin and it may act as a sensitizer. The lethal dose 50 percent kill is $310 \mathrm{mg} \cdot \mathrm{kg}^{-1}$ and $100 \mathrm{mg} \cdot \mathrm{kg}^{-1}$ for rat and mouse respectively.

Liquid chromatography is the most widely used method for analysis of CHD [6]; UV detection around $250 \mathrm{~nm}$ is used for quantitative assays [7-9], while for the detection of impurities, mass spectrometry or photodiode array detectors are employed [10,11]. Other methods reported in the literature include fluorometry [12] and direct UV spectroscopy [13]; both of them have several disadvantages: lack of sensitivity, serious interference.

There are many reports about the determination of CHD in biological fluids using high performance liquid chromatography with a UV detector (HPLC-UV) $[8,9$, 14-18] and gas chromatography mass spectrometry (GC-MS) [19-23].

Column used are generally C18 [11,14,15,24], Amide [11] or phenyl [25]. Furthermore, reversed-phase ion-pair system is frequently used.

However, as pCA is the principal product degradation, and because of his toxicity and to be in line with actual recommendation for genotoxic impurities [26], it is important to quantify pCA in CHD solution. Therefore, we describe hereafter a new very sensible HPLC-UV method without the need of additional mobile-phase amine modifiers or ion-pairing reagents, with good resolution between pCA and CHD, symmetry peak of the compo- unds and short run time. To prove the reliability of this method, $\mathrm{CHD}$ and pCA were analyzed in medical products.

\section{Materials and Methods}

\subsection{Chemicals and Reagents}

CHD gluconate solution (20\%, with a density of 1.06$)$ was purchased from Sigma (St Quentin-Fallavier, France) and stored at $4{ }^{\circ} \mathrm{C}$ in the dark. Methanol and formic acid was of analytical grade from Carlo Erba (Val de Reuil, France). Other chemicals used were of analytical grade.

Seven pharmaceutical specialities: Prexidine $0.12 \%{ }^{\circledR}$ mouthrinses (Expanscience, France), Septisol ${ }^{\circledR}$ eye drops (Merck, France), Correctol 0.1\%® eye drops (Alcon, France), Sophtal ${ }^{\circledR}$ eye drops (Alcon, France), Septeal ${ }^{\circledR}$ for topical application (Pierre Fabre Dermatologie, France), Chlorhexidine Aqueuse Gilbert à $0.05 \%{ }^{\circledR}$ for topical application (Gilbert, France) and Dacrine ${ }^{\circledR}$ eye drops (McNeil, France) were purchased in pharmacy. CHD is used as active substance except in Septisol ${ }^{\circledR}$, Correctol $0.1 \%{ }^{\circledR}$ and Sophtal ${ }^{\circledR}$ where it is used as excipient.

\subsection{Apparatus and Chromatographic Conditions}

HPLC-UV analyses were performed using a Dionex ${ }^{\circledR}$ Summit liquid chromatograph (Dionex Corp, Sunnyvale, CA, USA), equipped with a vacuum solvent degassing unit, a binary high pressure gradient pump P680, an ASI100 automated sample injector, an UVD340U variable wavelength UV-VIS detector.

Chromatographic separations were carried out on a Luna ${ }^{\circledR} 150 \mathrm{~mm} \times 3 \mathrm{~mm}$ i.d. column packed with $3 \mu \mathrm{m}$ $\mathrm{CN}$ (cyano) particles (Phenomenex ${ }^{\circledR}$ ), guarded by an on-line filter. Data were collected and analyzed using the Chromeleon ${ }^{\circledR}$ software v6.50SP4 from Dionex ${ }^{\circledR}$.

Since it is known that amines tend to form stable salts with acetic acid, ammonium acetate and phosphate salts, the mobile phases for chlorhexidine quantitative assay consisting of methanol:water $(55: 45, \mathrm{v} / \mathrm{v})$ with sodium chloride with $0.02 \%$ of formic acid $(\mathrm{pH}=3)$ and pumped at a flow rate of $0.5 \mathrm{ml} / \mathrm{min}$.

Wavelengths for pCA and for CHD are 238 and $255 \mathrm{~nm}$ respectively.

\subsection{Sample Preparation}

Pharmaceutical specialities were directly injected $(20 \mu \mathrm{l})$ into the chromatograph system (without any extraction) after or not dilution.

\subsection{Mobile Phase}

Published HPLC assays also suffer from quantitation 
problems caused by irreversible adsorption of CHD onto the silica-based reversed phase (RP)-HPLC columns [27, 28]. These problems can be overcome by adding $\mathrm{NaCl}$ to the mobile phase [28] and explain the presence of this compound in our mobile phase. The effect of $\mathrm{NaCl}$ can be explained by the two simultaneously occurring processes: the salting out effect, and the electrostatic interactions between polar molecules and salt ions in sample solution [29].

Chlorhexidine is a dicationic compound with $\mathrm{Ka} 1=$ $6.3 \times 10^{-3}$ and $\mathrm{Ka} 2=5.0 \times 10^{-11}$ and is almost completely ionized $(1+)$ at $\mathrm{pH}=3, \mathrm{pH}$ of our mobile phase.

Because chlorhexidine and some of its degradation products are strongly basic, they are intensely retained on most silica-based reversed phase columns [30]; the difficulty was overcome by using a cyano column and an acid mobile phase $(\mathrm{pH}=3)$, without the need to use ion-pairing reagents in the mobile phase. It is known that chlorhexidine is quite stable at this low $\mathrm{pH}$ (some HPLC methods use $\mathrm{pH}=2.5$ ) [9].

\subsection{Statistics}

Results are presented as the mean \pm SD and results were analyzed using Excel ${ }^{\circledR}$ 10, WinStat ${ }^{\circledR}$ v2003.1 and Chromeleon ${ }^{\circ}$. A p value $<0.05$ was considered as significant.

\subsection{Validation Criteria}

\subsubsection{Linearity}

Working standards were prepared by dilution in water and taking account of density for CHD gluconate. Height reference samples were used for calibration curves of CHD (0.53 to $21.20 \mathrm{mg} / \mathrm{l})$ and $\mathrm{pCA}(0.01$ to $10.0 \mathrm{ng} / \mathrm{ml})$. Each determination was done in triplicate. The calibration factors were calculated according to least-squares linear regression .

\subsubsection{Precision and Accuracy}

Precision was determined for both inter- and intra-day variability. These measurements were made by HPLC analysis of CHD (5.3 and $12.72 \mathrm{mg} / \mathrm{l})$ and pCA (0.50, and $2.0 \mathrm{mg} / \mathrm{l}$ ), on three consecutive days (inter-day variation or reproducibility) or during the same day for intraday variation determination (repeatability).

\subsubsection{Limit of Detection (LOD) and Limit of Quantification (LOQ)}

Standard curves were prepared for the two analytes and the following equation were used to calculate the LOD and the LOQ for each compound [31]:

$$
\mathrm{LOD}=3.3 \sigma / S ; \mathrm{LOQ}=10 \sigma / S
$$

where $\sigma$ is the standard deviation of the response (estimated from the standard deviation of y-intercepts of regression lines) and $\mathrm{S}$ is the slope of the standard curve.

At the LOQ, bias and precision should not exceed $12 \%$ [32].

\section{Results}

To optimise the mobile phase, the influence of concentration of methanol and sodium chloride was first studied.

\section{Discussion}

Based on the results presented in Figures 2 and $\mathbf{3}$ and in Table 1, the concentration of methanol in the mobile phase was chosen as $55 \%$ in order to have a short run time (less than 5 minutes) and a good resolution (about 4.1) (Figure 4) between the two components.

There is few influence of sodium chloride concentration on retention time and peak asymmetry of pCA and CHD. It is noted that asymmetry for CHD (1.7) and for pCA (1.3) is very good with this cyano column from Phenomenex ${ }^{\circledR}$ (Table 2). However, height of CHD decrease, when concentration of sodium chloride increase, while pCA height peak increase too. A concentration of $12 \%$ of sodium chloride was chosen, the goal is to avoid an important decrease of CHD and to increase the sensibility of pCA detection, especially because of its toxicity.

Linearity of CHD is very good, from 0.5 up to $21.2 \mu \mathrm{g} / \mathrm{l}$ (Table 3). This range is in the same order of that describes by Hebert et al. [7], but with a run time of 22 minutes. Some authors $[9,11,14,30]$ present better sensibility for CHD (LOD is $0.05 \mathrm{mg} / \mathrm{l}$ ) quantitation but they don't quantify pCA. But for Usui [33] which works with $\mathrm{LC} / \mathrm{MS}$, it was difficult to estimate the reliable values at the concentration range below $0.1 \mathrm{mg} / \mathrm{l}$. Only Below and Kramer [16] present a dosage method for both pCA and CHD, with a run time of 20 minutes.

Linearity of pCA is very good (range from 0.05 to $10 \mathrm{mg} / \mathrm{l})$, for a product known to be difficult to be analysed $[9,30]$ and with LOD and LOQ very low.

This method has been applied to a CHD solution included into pharmaceutical specialities (Table 4) (Figure 5). In conclusion, we present a validated method for dosage of CHD and its major impurity pCA. No interference has been reported, and the analysis of direct injection of solution, without any treatment except an eventually dilution is achieved in less than five minutes. In all cases, pCA was less than LOD, and CHD is in the range generally accepted in pharmaceutical products $(95 \%$ - 


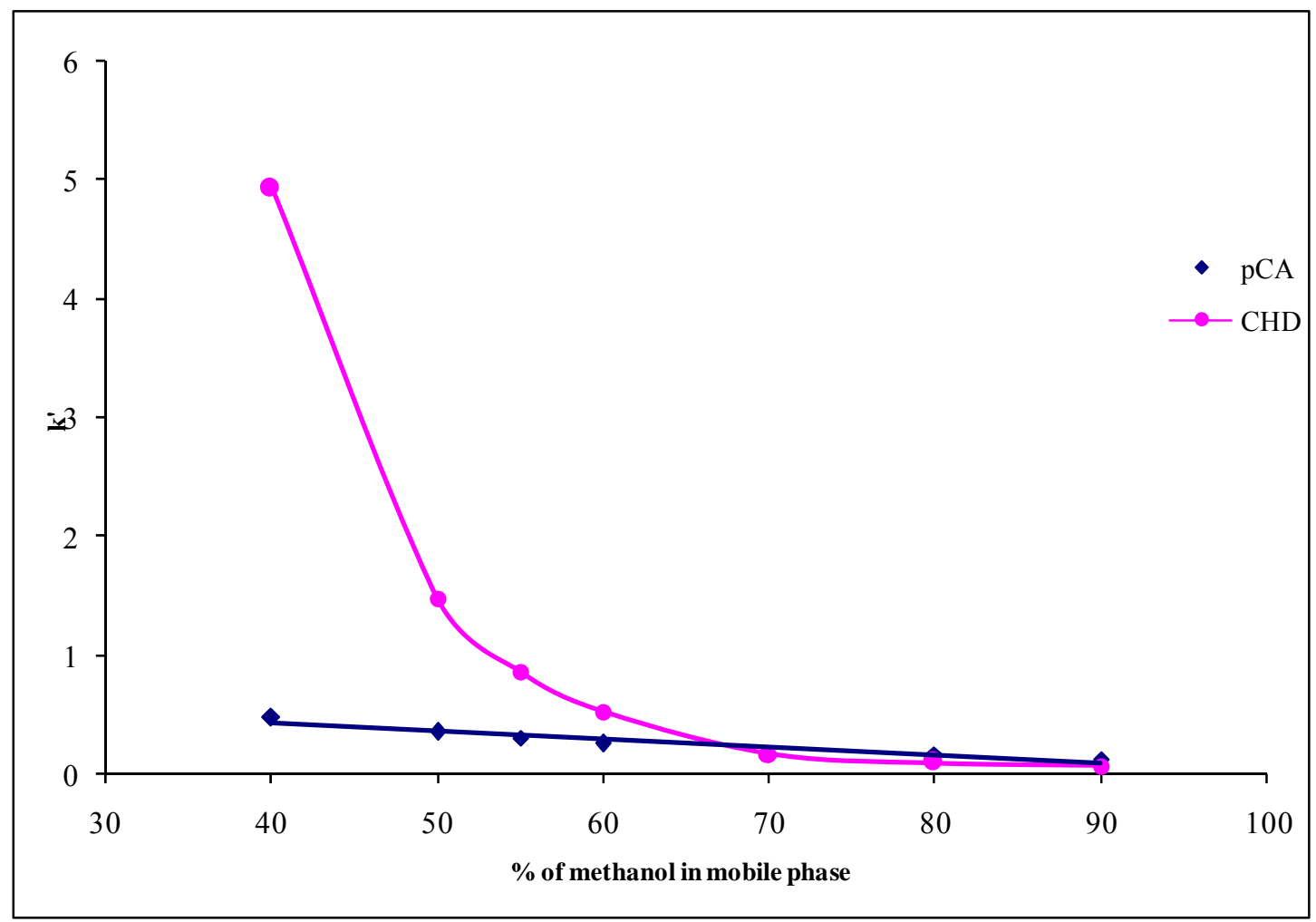

Figure 2. Influence of the methanol content in the eluant (methanol: $8 \%$ of sodium solution with $0.02 \%$ of formic acid (pH = 3) on the capacity factor of CHD and pCA (Luna CN, $150 \times 3.0 \mathrm{~mm}, 3 \mu \mathrm{m}, 0.5 \mathrm{ml} / \mathrm{min}$ ); k' (capacity factor) for $\bullet \mathrm{pPC}$ and $\bullet$ CHD.

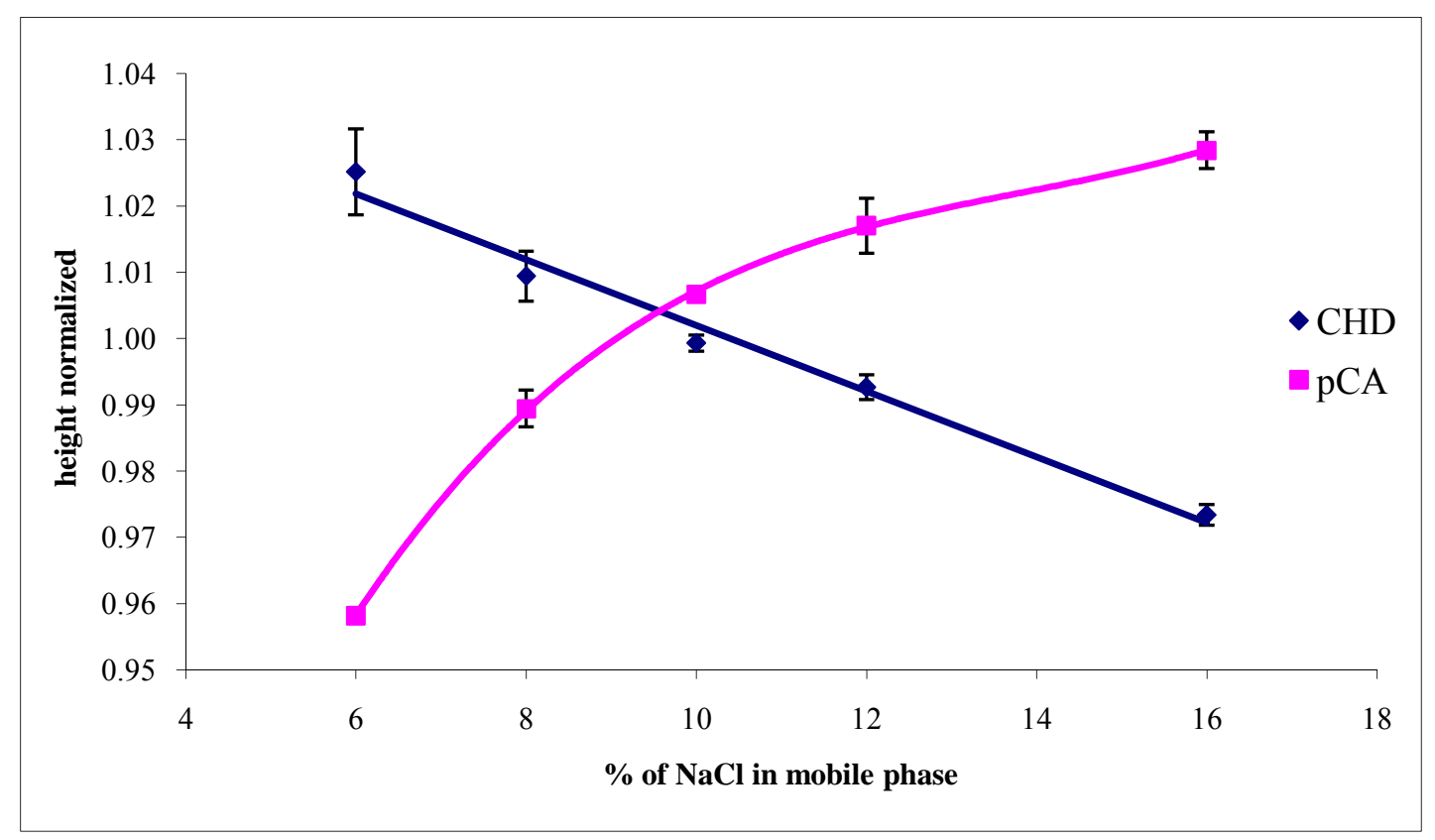

Figure 3. Influence of the sodium chloride content in the eluant (55:45 of methanol: sodium solution with $0.02 \%$ of formic acid $(\mathrm{pH}=3)$ on the variation of height $( \pm \mathrm{SD})$ normalized by mean of $\bullet \mathrm{pPC}$ and $\bullet \mathrm{CHD}$ (Luna CN, $150 \times 3.0 \mathrm{~mm}, 3 \mu \mathrm{m}$, $0.5 \mathrm{ml} / \mathrm{min}$ ). 


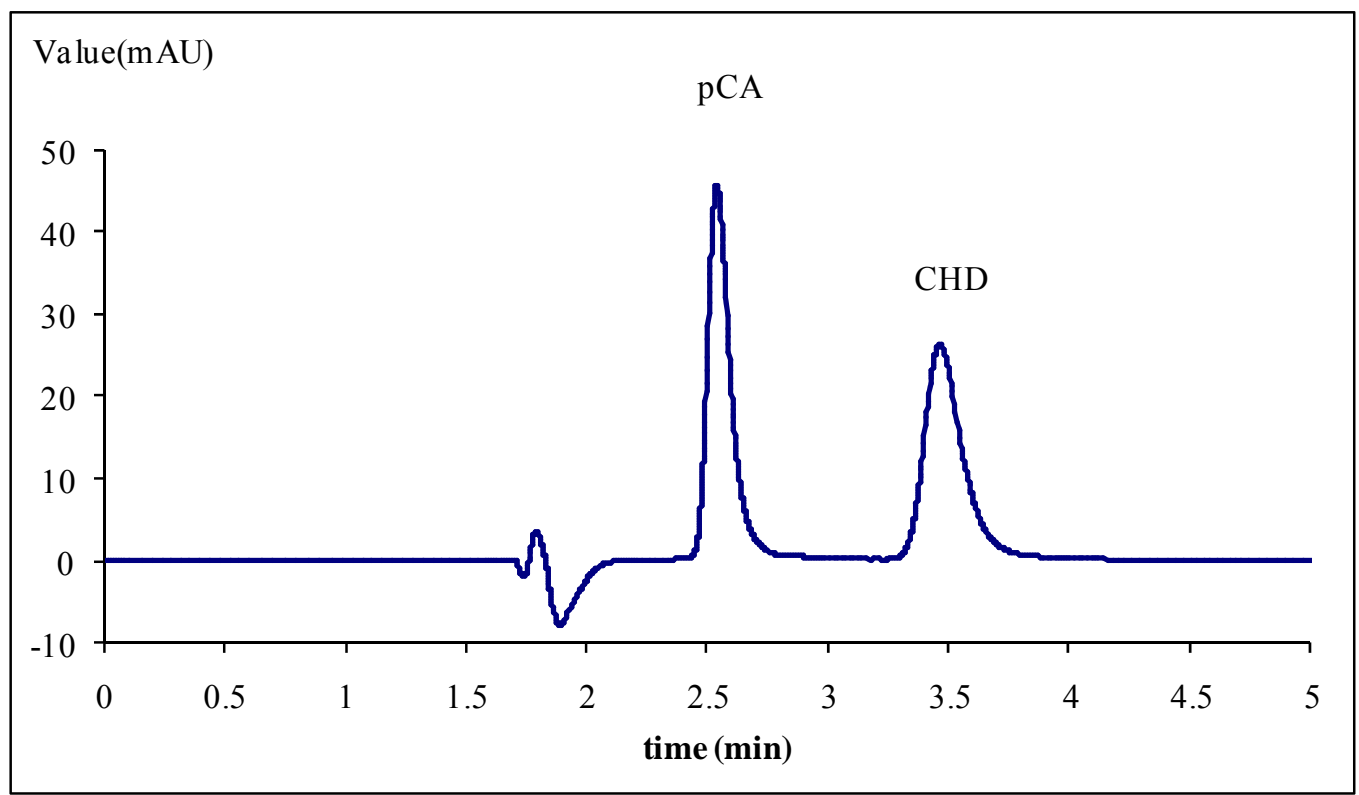

Figure 4. Typical chromatogram of a solution with pCA (1 mg/l) and CHD (5 mg/l).

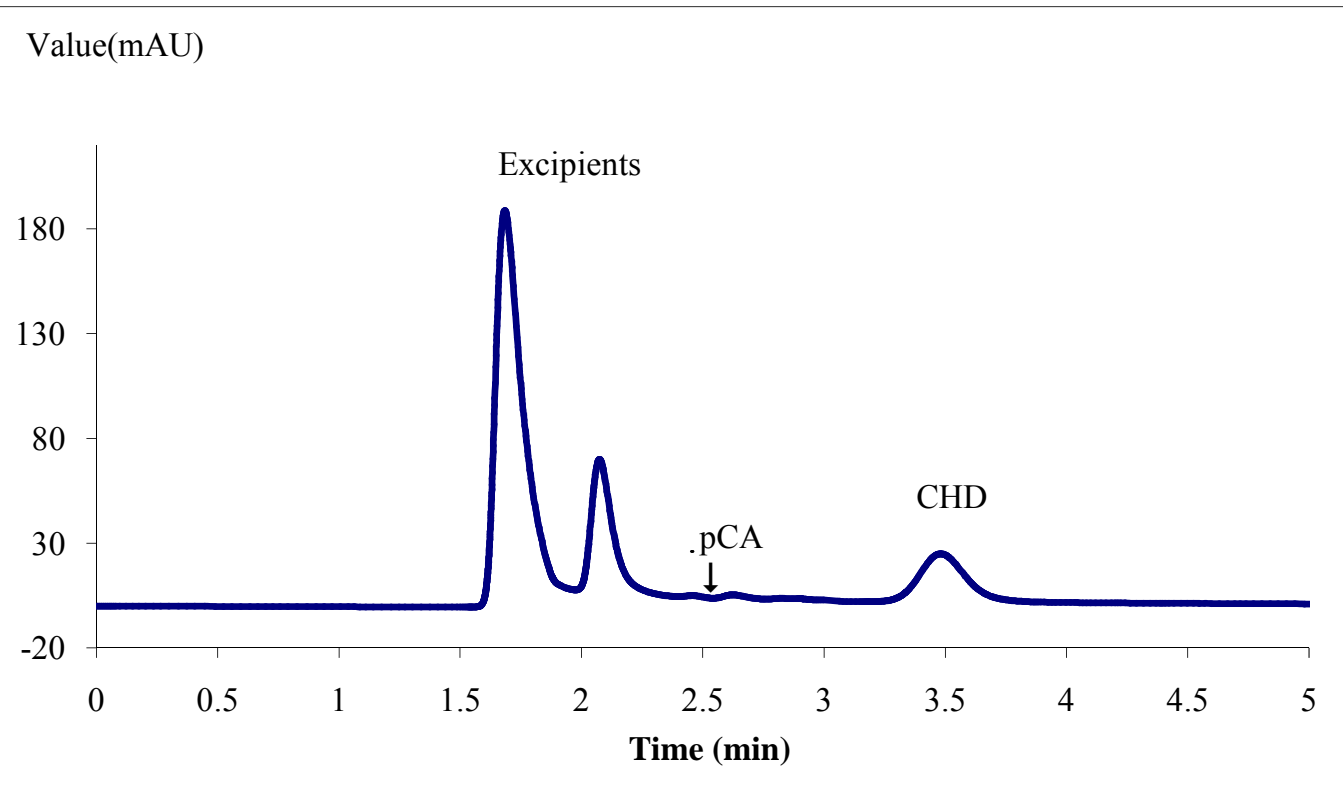

Figure 5. Chromatogram of sophtal solution, directly injected. The two first peaks are excipients. pCA is not detected.

Table 1. Intra-day and inter-days precision and accuracy.

\begin{tabular}{|c|c|c|c|c|c|}
\hline \multirow{3}{*}{ Substance } & Theoretical concentrations & intra-day precision $(n=9)$ & $\begin{array}{c}\text { inter-day precision }(\mathrm{n}=3) \\
\text { ( } 3 \text { days) }\end{array}$ & RSD & \multirow{3}{*}{ Accuracy (\%) } \\
\hline & $(\mu \mathrm{g} / \mathrm{l})$ & \multicolumn{2}{|c|}{ Concentrations found } & $(\%)$ & \\
\hline & \multicolumn{4}{|c|}{ (mean \pm S.D.) } & \\
\hline \multirow{2}{*}{ pCA } & 0.50 & $0.511 \pm 0.023$ & & 0.90 & 97.8 \\
\hline & 2.0 & & $2.022 \pm 0.084$ & 4.16 & 98.9 \\
\hline \multirow{2}{*}{ CHD } & 5.30 & & $5.203 \pm 0.152$ & 2.92 & 101.9 \\
\hline & 12.72 & $12.90 \pm 0.14$ & & 0.56 & 98.6 \\
\hline
\end{tabular}


Table 2. Influence of sodium chloride content in the eluant (55:45 of methanol:sodium chloride solution with $0.02 \%$ of formic acid $(\mathrm{pH}=3)$ ) on the variation (expressed as mean \pm standard deviation for a triplicate injection) of retention time (TR) in minutes, height (H) in mAU and asymmetry (As) of pCA and CHD.

\begin{tabular}{|c|c|c|c|c|c|c|c|c|c|c|c|c|}
\hline \multirow{2}{*}{$\%$ o $\mathrm{NaCl}$} & \multicolumn{2}{|c|}{ TR CHD } & \multicolumn{2}{|c|}{$\mathrm{H} \mathrm{CHD}$} & \multicolumn{2}{|c|}{ As CHD } & \multicolumn{2}{|c|}{ TR pCA } & \multicolumn{2}{|c|}{$\mathrm{H} \mathrm{pCA}$} & \multicolumn{2}{|c|}{ As pCA } \\
\hline & $\mathrm{m}$ & SD & $\mathrm{m}$ & SD & $\mathrm{m}$ & SD & $\mathrm{m}$ & SD & $\mathrm{m}$ & SD & $\mathrm{m}$ & SD \\
\hline 6 & 3.54 & 0.00 & 533.6 & 3.38 & 1.69 & 0.01 & 2.57 & 0.00 & 86.8 & 0.10 & 1.38 & 0.06 \\
\hline 8 & 3.48 & 0.00 & 525.4 & 1.96 & 1.69 & 0.01 & 2.56 & 0.02 & 89.6 & 0.25 & 1.37 & 0.01 \\
\hline 10 & 3.48 & 0.00 & 520.2 & 0.64 & 1.70 & 0.01 & 2.55 & 0.00 & 91.2 & 0.00 & 1.34 & 0.01 \\
\hline 12 & 3.47 & 0.00 & 516.7 & 0.96 & 1.69 & 0.01 & 2.54 & 0.00 & 92.1 & 0.38 & 1.32 & 0.01 \\
\hline 16 & 3.48 & 0.00 & 506.7 & 0.80 & 1.66 & 0.01 & 2.53 & 0.01 & 93.2 & 0.25 & 1.31 & 0.00 \\
\hline
\end{tabular}

Table 3. Linearity, limits of detection and quatification of standard curvese.

\begin{tabular}{cccccc}
\hline Substance & Linear range $(\mathbf{m g} / \mathbf{l})$ & $\begin{array}{c}\text { Calibration equation } \\
(\mathbf{y}=\text { area, } \mathbf{x}=\mathbf{m g} / \mathbf{l})\end{array}$ & $\begin{array}{c}\text { Correlation } \\
\text { coefficients (r) }\end{array}$ & LOD (mg/l) & LOQ (mg/l) \\
\hline pCA & $0.05-10$ & $\mathrm{y}=5.5237 \mathrm{x}-0.1299$ & 0.99996 & 0.0035 \\
CHD & $0.53-21.2$ & $\mathrm{y}=1.6084 \mathrm{x}+1.2123$ & 0.99932 & 0.15 & 0.0105 \\
\hline
\end{tabular}

Table 4. CHD amounts in pharmaceutical specialities.

\begin{tabular}{cccc}
\hline & $\begin{array}{c}\text { CHD theoretical } \\
\text { concentration }(\mathrm{mg} / \mathrm{l})\end{array}$ & $\begin{array}{c}\text { CHD observed concentration }(\mathrm{mg} / \mathrm{l}) \\
(\%)\end{array}$ & 1174 \\
\hline Prexidine $0.12 \%$ & 1200 & 30.5 & 101.7 \\
Septisol & $30 *$ & 31.3 & 104.3 \\
Correctol 0.1\% & $30^{*}$ & 30 & 100.0 \\
Sophtal & $30 *$ & 4707 & 94.1 \\
Septeal 0.5\% & 5000 & 95.3 & 95.3 \\
Dacrine & 100 & 517 & 103.4 \\
\hline
\end{tabular}

* amounts of CHD generally used but not specified when CHD is used as excipients.

$105 \%)$.

\section{References}

[1] D. S. Paulson, "Efficacy Evaluation of a 4\% Chlorhexidine Gluconate as a Full-Body Shower Wash," American Journal of Infection Control, Vol. 21, No. 4, 1993, pp. 205-209. doi:10.1016/0196-6553(93)90033-Z

[2] J. M. Albandar, J. Rise, P. Gjermo and J. R. Johansen, "Radiographic Quantification of Alveolar Bone Level Changes. A 2-Year Longitudinal Study in Man," Journal of Clinical Periodontology, Vol. 13, No. 3, 1986, pp. 195-200. doi:10.1111/j.1600-051X.1986.tb01459.x

[3] P. Gjermo, "Chlorhexidine in Dental Practice," Journal of Clinical Periodontology, Vol. 1, No. 3, 1974, pp. 143152. doi:10.1111/j.1600-051X.1974.tb01250.x

[4] S. S. Block, "Disinfection, Sterilization and Preservation," Lea and Febiger, Philadelphia, 1991, p. 274.

[5] G. W. Denton, "Chlorhexidine," 5th Edition, Lippincott Williams \& Williams, Philadelphia, 2001, p. 32.

[6] F. A. Másquio Fiorentino, M. A. Corrêa and H. R. Nunes Salgado, "Analytical Methods for the Determination of Chlorhexidine: A Review," Critical Reviews in Analytical Chemistry, Vol. 40, No. 2, 2010, pp. $89-101$. doi:10.1080/10408340903232020

[7] V. R. Hebert, J. R. Middleton, E. Tomaszewska and L. K. Fox, "Methodology for Quantifying Residues of Chlor- hexidine in Raw Dairy Milk," Journal of Agricultural and Food Chemistry, Vol. 51, No. 3, 2003, pp. 567-570. doi:10.1021/jf020915s

[8] H. Tsuchiya, T. Miyazaki and S. Ohmoto, "High-Performance Liquid Chromatographic Analysis of Chlorhexidine in Saliva after Mouthrinsing," Caries Research, Vol. 33, No. 2, 1999, pp. 156-163. doi: $10.1159 / 000016510$

[9] T. Pesonen, J. Holmalahti and J. Pohjola, "Determination of Chlorhexidine in Saliva Using High-Performance Liquid Chromatography," Journal of Chromatography, Vol. 665, No. 1, 1995, pp. 222-225.

[10] L. K. Revelle, W. H. Doub, R. T. Wilson, M. H. Harris and A. M. Rutter, "Identification and Isolation of Chlorhexidine Digluconate Impurities," Pharmaceutical Research, Vol. 10, No. 12, 1993, pp. 1777-1784. doi:10.1023/A:1018986501194

[11] Y. Ha and A. P. Cheung, "New Stability-Indicating High Performance Liquid Chromatography Assay and Proposed Hydrolytic Pathways of Chlorhexidine," Journal of Pharmaceutical and Biomedical Analysis, Vol. 14, No. 8-10, 1996, pp. 1327-1334. doi:10.1016/S0731-7085(96)01763-3

[12] J. de Vries, J. Ruben and J. Arends, "Determination of Chlorhexidine in Saliva and in Aqueous Solutions," Caries Research, Vol. 25, No. 6, 1991, pp. 410-414. doi:10.1159/000261403

[13] J. E. Jensen and F. Christensen, "A Study of the Elimina- 
tion of Chlorhexidine from the Oral Cavity Using a New Spectrophotometric Method," Journal of Periodontal Research, Vol. 6, No. 4, 1971, pp. 306-311. doi:10.1111/j.1600-0765.1971.tb00622.x

[14] K. Kudo, N. Ikeda, A. Kiyoshima, Y. Hino, N. Nishida and N. Inoue, "Toxicological Analysis of Chlorhexidine in Human Serum Using HPLC on a Polymer-Coated ODS Column," Journal of Analytical Toxicology, Vol. 26, No. 2, 2002, pp. 119-122.

[15] L. R. Brougham, H. Y. Cheng and K. A. Pittman, "Sensitive High-Performance Liquid Chromatographic Method for the Determination of Chlorhexidine in Human Serum and Urine," Journal of Chromatography, Vol. 383, No. 2, 1986, pp. 365-373.

[16] H. Below, N. Lehan and A. Kramer, "HPLC Determination of the Antiseptic Agent Chlorhexidine and Its Degradation Products 4-Chloroaniline and 1-Chloro-4-Nitrobenzene in Serum and Urine," Microchimica Acta, Vol. 146, No. 2, 2004, pp. 129-135.

[17] Y. W. Lam, D. C. Chan, S. Y. Rodriguez, J. H. Lintakoon and T. H. Lam, "Sensitive High-Performance Liquid Chromatographic Assay for the Determination of Chlorhexidine in Saliva," Journal of Chromatography, Vol. 612, No. 1, 1993, pp. 166-171.

[18] P. Wainwright and M. Cooke, "Direct Determination of Chlorhexidine in Urine by High-Performance Liquid Chromatography," The Analyst, Vol. 111, No. 11, 1986, pp. 1343-1344. doi:10.1039/an9861101343

[19] H. Matsushima, K. Sugimoto, K. Shibata and N. Sakurai, "Determination by Mass Fragmentography of the Chlorhexidine in Biological Samples," Japanese Journal of Hygiene, Vol. 37, No. 5, 1982, pp. 762-767.

[20] V. G. Alder, D. Burman, R. A. Simpson, J. Fysh and W. A. Gillespie, "Comparison of Hexachlorophane and Chlorhexidine Powders in Prevention of Neonatal Infection," Archives of Disease in Childhood, Vol. 55, No. 4, 1980, pp. 277-280. doi:10.1136/adc.55.4.277

[21] E. Read, "A Note of Hibitane Assay with Final Iodination," Methodological Surveys in Biochemistry, Chichester Ellis, Horwwod, 1978.

[22] W. K. Gavlick and P. K. Davis, "Gas Chromatographic Determination of p-Chloroaniline in a Chlorhexidine Digluconate-Containing Alcohol Foam Surgical Scrub Product," Journal of AOAC International, Vol. 77, No. 3, 1994, pp. 583-586.

[23] A. Ono, "Gas-Liquid Chromatographic Separation of Toluidine, Chloroaniline and Dichloroaniline Isomers on Various Stationary Phases Including Heteroaromatic
Compounds," Analyst, Vol. 107, No. 1275, 1982, pp. 600-605.

[24] Y. Zhu, Y. Yang and Q. Qi, "Determination of Chlorhexidine Acetate in Disinfectant by High Performance Liquid Chromatography," Wei Sheng Yan Jiu, Vol. 32, No. 1, 2003, pp. 51-87.

[25] L. Havlíková, L. Matysová, L. Nováková, R. Hájková and P. Solich, "HPLC Determination of Chlorhexidine Gluconate and p-Chloroaniline in Topical Ointment," Vol. 43, No. 3, 2007, pp. 1169-1173.

[26] European Medicines Agency, "Guideline on the Limits of Genotoxic Impurities,” EMEA/CHMP/QWP/251344/2006, 2006, pp. 1-8.

[27] A. P. Cheung, R. Mavar, C. Carlson and W. K. Chiang, "Problems Affecting the Liquid Chromatographic Quantitation of Chlorhexidine Digluconate in Ophthalmic Solutions," Journal of Pharmaceutical and Biomedical Analysis, Vol. 9, No. 1, 1991, pp. 41-45. doi:10.1016/0731-7085(91)80235-2

[28] L. E. Stevens, J. R. Durrwachter and D. O. Helton, “Analysis of Chlorhexidine Sorption in Soft Contact Lenses by Catalytic Oxidation of [14C]Chlorhexidine and by Liquid Chromatography," Journal of Pharmaceutical Sciences, Vol. 75, No. 1, 1986, pp. 83-86. doi:10.1002/jps.2600750120

[29] L. Zhao, L. Zhu and H. K. Lee, "Analysis of Aromatic Amines in Water Samples by Liquid-Liquid-Liquid Microextraction with Hollow Fibers and High-Performance Liquid Chromatography," Journal of Chromatography, Vol. 963, No. 1-2, 2002, pp. 239-248. doi:10.1016/S0021-9673(02)00544-7

[30] F. M. Musteata and J. Pawliszyn, "Assay of Stability, Free and Total Concentration of Chlorhexidine in Saliva by Solid Phase Microextraction," Journal of Pharmaceutical and Biomedical Analysis, Vol. 37, No. 5, 2005, pp. 1015-1024. doi:10.1016/j.jpba.2004.09.055

[31] ICH Harmonised Tripartite Guideline, "Validation of Analytical Procedures: Methodology: ICH Topic Q2B," CPMP/ICH/281/95, 1996, pp. 1-15.

[32] J. Vial and A. Jardy, "Experimental Comparison of the Different Approaches to Estimate LOD and LOQ of an HPLC Method," Analytical Chemistry, Vol. 71 No. 14, 1999, pp. 2672-2677.

[33] K. Usui, T. Hishinuma, H. Yamaguchi, N. Tachiiri and J. Goto, "Determination of Chlorhexidine (CHD) and Nonylphenolethoxylates (NPEOn) Using LC-ESI-MS Method and Application to Hemolyzed Blood," Journal of Chromatography, Vol. 831, No. 1-2, 2006, pp. 105-109. 